\title{
Knowledge regarding neonatal jaundice among a sample of mothers attending some Primary Health Care centers /Baghdad Maral F Thabit (FICMS, FM) ${ }^{1}$
}

\begin{abstract}
Background: Neonatal jaundice is most common condition requiring medical evaluation in a newborn and it is yellowish discoloration of the white part of the eyes and skin in a newborn baby due to high bilirubin levels.

Objective: To assess the knowledge regarding neonatal jaundice in a sample of mothers attending some Primary Health Care centers, Baghdad.

Patients and Methods: A cross-sectional study was conducted including 265 mothers attending some primary health care centers in Baghdad during November and December 2016. They were subjected to previously structured questionnaire covering many aspects of neonatal jaundice distributed in 3 main domains and the mother's responses were gathered and then statistically analysed by frequency, percentages and percent score for each question responses and domain and the overall knowledge mean score.

Results: Family and relatives were the main source of information $39.7 \%$ and the results revealed that the mean percent score for knowledge responses was $74 \%$ for definition of jaundice, $68 \%$ for complications of jaundice and $71 \%$ for ways of treatment.The mean overall percent score for knowledge was $71 \%$.

Conclusion: Good mean overall knowledge level regarding neonatal jaundice among study group.

Keywords: Mothers ,Neonatal jaundice ,Knowledge

Corresponding Author: maral.fthabit@yahoo.com

Received: $5^{\text {th }}$ March 2019

Accepted: $12^{\text {th }}$ May 2019

\footnotetext{
${ }^{1}$ Institute of Medical Technology-Baghdad - Iraq.
}

\section{Introduction}

Neonatal jaundice referred to as neonatal hyperbilirubineia and physiological jaundice of the newborn is a yellow discoloration of the skin and the white part (the sclera) of the eyes[1] Neonatal jaundice is one of the most common and important conditions during the neonatal period $[2,3]$. Neonatal jaundice is

still a leading cause of preventable brain damage, physical and mental handicap, and early death among infants in many communities [3] It is also a significant cause of neonatal morbidity world-wide and is estimated to be present in $60 \%$ of term neonates and $80 \%$ of preterm babies $[1,4]$.
\end{abstract}


Physiologic jaundice in newborns most commonly occurs because their livers are not mature enough to remove bilirubin from the blood[5]. Bilirubin formed when the body breaks down old red blood cells. A normal increase in red blood cell breakdown and the fact that their immature livers are not efficient at removing bilirubin from the bloodstream [5], this type of bilirubin is called unconjugated or indirect bilirubin [6].This form of bilirubin is not easily removed from the baby's body. The baby's liver changes this unconjugated bilirubin into conjugated or direct bilirubin, which is easier to excrete [6]. The liver of a newborn baby is immature, so the job of conjugating and removing bilirubin is not done completely well, this causes elevation of bilirubin [5] when jaundice is due to these factors alone, it is termed physiologic jaundice. Neonatal jaundice can be seen in cases of maternalfetal blood type incompatibility. The mother's body will actually produce antibodies that attack the fetus's blood cells[6]. Nowadays, newborns are discharged early from hospitals, therefore mothers play an important role to recognize jaundice and control it properly [7]. Aim of study to assess level of knowledge of mothers regarding neonatal jaundice attending some primary health care centers, Baghdad.

\section{Patients and Methods}

A cross sectional descriptive study included (265) mothers attending some primary health care centers, Baghdad during November and December 2016.
They were selected randomly by simple random sampling technique and invited to participate after clarifying the purpose behind the study, assuring high confidentiality and willing participants gave verbal consents and they completed a comprehensive previously prepared self-structured questionnaire in designated areas of health centers.

The questionnaire consists of sociodemographic characteristics and different questions covering the knowledge regarding neonatal jaundice.

\section{Statistical analysis}

Statistical analysis was done by(frequency and percentages) for each question responses and a score of [3] was given for each yes answer , [ 2] for answering don't know and [1]for answering ( No ). The percent score for mothers' responses in each specific item was calculated according to the following equation: Total scores for all participants in the item X 100 / maximum possible score for all participants in the same item. Where total scores for all participants in the item $=[($ No. of no x 1) + (No. of don't know x 2) + (No. of yes $x 3$ )]. And maximum possible scores for all participants in the same item $=[$ No. of total mothers $\mathrm{x}$ 3], based on Triple Likert Scale and also overall percent score was calculated for each domain (mean percent score for all responses for each domain) and after approximation, the percent score categorized as students who had score less than $60 \%$ considered as poor, $60 \%$ to $69 \%$ as fair, while those with $70 \%$ to $79 \%$ were considered as good and $80 \%$ to $89 \%$ as very $\operatorname{good}[8]$. 


\section{Results}

The total number of included mothers was (265). The highest percentage $43.8 \%$ in the age group 20-29years ,34.7\% were house wives , $34.7 \%$ with secondary level of education , $69.4 \%$ delivered by normal vaginal delivery ,38.8\% had positive previous babies with history of neonatal jaundice and $36.2 \%$ of mothers stated that skin in the site for jaundice detection as shown in Table (1).

Table (1): Distribution of mothers regarding socio-demographic characteristics and jaundice related characteristics $(\mathrm{N}=265)$.

\begin{tabular}{|l||l||l|}
\hline \multicolumn{1}{|c||}{$\begin{array}{c}\text { Socio-tomographic and jaundice related } \\
\text { characteristics }\end{array}$} & No. & \% \\
\hline Age of mothers(years) & & \\
\hline$<20$ & 47 & 17.8 \\
\hline $20-29$ & 116 & 43.8 \\
\hline \hline $30-39$ & 83 & 31.3 \\
\hline$\geq 40$ & 19 & 7.1 \\
\hline \hline Mothers occupations & & \\
\hline Manual worker & 46 & 17.3 \\
\hline \hline Officer & 88 & 33.2 \\
\hline \hline House-wives & 92 & 34.7 \\
\hline \hline Private work & 39 & 14.8 \\
\hline Education of mothers & & \\
\hline \hline Can read and write & 46 & 17.3 \\
\hline \hline Primary & 88 & 33.2 \\
\hline Secondary & 92 & 34.7 \\
\hline \hline College and more & 39 & 14.8 \\
\hline Type of delivery of the last baby & & \\
\hline \hline Normal vaginal delivery & 184 & 69.4 \\
\hline Cesarean section & 69 & 26 \\
\hline \hline Others & 12 & 4.6 \\
\hline \hline Any previous history of neonatal jaundice & & \\
\hline \hline Yes & 103 & 38.8 \\
\hline \hline No & 162 & 61.2 \\
\hline Site for jaundice detection & & \\
\hline Skin & 96 & 36.2 \\
\hline \hline Eye & 85 & 32.1 \\
\hline \hline Face & 78 & 29.5 \\
\hline \hline Palms and feet & 6 & 23.8 \\
\hline & & \\
\hline
\end{tabular}

The main source of information regarding neonatal jaundice was family /relatives
$39.7 \%$, followed by health workers $30.6 \%$ as shown in Table (2). 
Knowledge regarding neonatal jaundice among a sample of mothers attending some Primary Health Care centers /Baghdad

Table (2): Distribution of mothers regarding source of information regarding neonatal jaundice $(\mathrm{N}=265)$.

\begin{tabular}{|l||l||l|}
\hline \multicolumn{1}{|c||}{ Source of information } & No & \% \\
\hline \hline Health workers & 81 & 30.6 \\
\hline \hline TV/Radio & 38 & 14.4 \\
\hline \hline Family /relatives & 105 & 39.7 \\
\hline \hline Internet & 43 & 16.3 \\
\hline \hline Others & 17 & 6.5 \\
\hline
\end{tabular}

The correct knowledge responses of immediate medical consultation and jaundice mothers regarding definition of neonatal is the yellowish coloration of face and eye of jaundice was highest $66.7 \%$ and $57.7 \%$ with the newborn. The overall percent score for percent score $85 \%, 78 \%$ regarding this domain was $74 \%$ as shown in Table (3). appearance of jaundice in the first day needs

Table (3): Knowledge of mothers regarding definition of neonatal jaundice ( $\mathrm{N}=265)$.

\begin{tabular}{|c|c|c|c|c|c|c|c|}
\hline \multirow[t]{2}{*}{ Definition of neonatal jaundice } & \multicolumn{2}{|c|}{ Yes } & \multicolumn{2}{|r|}{ No } & \multicolumn{2}{|c|}{ Don't know } & \multirow{2}{*}{$\begin{array}{c}\text { Percent } \\
\text { score } \\
\end{array}$} \\
\hline & No & $\%$ & No & $\%$ & No & $\%$ & \\
\hline $\begin{array}{l}\text { Jaundice is yellowish coloration of face } \\
\text { and eyes of the newborn }\end{array}$ & 153 & $\begin{array}{c}57.7 \\
\end{array}$ & 61 & 23 & $\overline{551}$ & 19.3 & 78 \\
\hline $\begin{array}{l}\text { It is a common problem in the newly } \\
\text { born babies }\end{array}$ & 86 & 32.4 & 42 & 15.9 & 137 & 51.7 & 72 \\
\hline $\begin{array}{l}\text { Appearance of jaundice in the first day } \\
\text { needs immediate medical consultation }\end{array}$ & 177 & 66.7 & 35 & 13.3 & 53 & 20 & 85 \\
\hline $\begin{array}{c}\text { It is normal to continue neonatal } \\
\text { jaundice for } 8 \text { week }\end{array}$ & 54 & 20.3 & $\begin{array}{l}10 \\
2\end{array}$ & 38.5 & 109 & 41.2 & 61 \\
\hline $\begin{array}{l}\text { Jaundice necessitate many tests for } \\
\text { mothers and neonatal }\end{array}$ & 89 & 33.6 & 22 & 8.3 & 154 & 58.1 & 75 \\
\hline
\end{tabular}

$*$ Overall percent score $=74$

The knowledge responses of mothers regarding complications of neonatal jaundice were disappointing. The highest correct percentage of responses $46.4 \%$ with percent score $76 \%$ regarding death followed by brain damage $42.2 \%$ with percent score $69 \%$ while the lowest percentage of correct responses $27.2 \%$ with percent score $61 \%$ for deafness .The overall percent score for this domain was $68 \%$ as shown in Table (4). 
Knowledge regarding neonatal jaundice among a sample of mothers attending some Primary Health Care

Table (4): Knowledge of mothers regarding complications of neonatal jaundice ( $\mathrm{N}=265)$.

\begin{tabular}{|l||c||c||c|c||c||c||c||}
\hline \multirow{2}{*}{$\begin{array}{c}\text { Complications of neonatal } \\
\text { jaundice }\end{array}$} & \multicolumn{2}{|c|}{ Yes } & \multicolumn{2}{c|}{ No } & \multicolumn{2}{c||}{ Don't know } & \multicolumn{1}{c|}{$\begin{array}{c}\text { Percent } \\
\text { score }\end{array}$} \\
\cline { 2 - 9 } & No & $\%$ & No & $\%$ & No & $\%$ & \\
\hline \hline Brain damage & 112 & 42.2 & 91 & 34.4 & 62 & 23.4 & 69 \\
\hline Convulsions & 97 & 36.6 & 86 & 32.4 & 82 & 31 & 68 \\
\hline \hline Mental retardation & 78 & 29.4 & 90 & 34 & 97 & 36.6 & 65 \\
\hline \hline Deafness & 72 & 27.2 & 116 & 43.8 & 77 & 29 & 61 \\
\hline \hline Physical retardation & 96 & 36.2 & 104 & 39.2 & 65 & 24.6 & 66 \\
\hline \hline Death & 123 & 46.4 & 48 & 18.2 & 94 & 35.4 & 76 \\
\hline
\end{tabular}

*Overall percent score $=68$

Knowledge responses regarding treatment of neonatal jaundice was highly correct regarding immediate doctor visit $68.3 \%$ with percent score $84 \%$ and exposure of the baby to fluorescent light $63 \%$ with percent score $81 \%$ although it was wrong perception, the

Table (5): Knowledge of mothers regarding treatment of neonatal jaundice ( $\mathrm{N}=265)$.

\begin{tabular}{|c|c|c|c|c|c|c|c|}
\hline \multirow[t]{2}{*}{ Treatment of neonatal jaundice } & \multicolumn{2}{|c|}{ Yes } & \multicolumn{2}{|c|}{ No } & \multicolumn{2}{|c|}{ Don't know } & \multirow{2}{*}{$\begin{array}{c}\text { Percent } \\
\text { score }\end{array}$} \\
\hline & No & $\%$ & No & $\%$ & No & $\%$ & \\
\hline Immediate doctor visit & 181 & 68.3 & 46 & 17.3 & 38 & 14.4 & 84 \\
\hline Exposure of the baby to sun & 122 & 46 & 59 & 22.3 & 84 & 31.7 & 75 \\
\hline Continuation of breast feeding & 75 & 28.3 & 68 & 25.7 & 122 & 46 & 68 \\
\hline Spontaneous recovery & 96 & 36.2 & 141 & 53.3 & 28 & 10.5 & 61 \\
\hline Frequent wash of the baby & 37 & 14 & 80 & 30.2 & 148 & 55.8 & 61 \\
\hline Exposure of the baby to fluorescent light & 167 & 63 & 56 & 21.2 & 42 & 15.8 & 81 \\
\hline Photo therapy & 98 & 37 & 66 & 25 & 101 & 38.2 & 70.7 \\
\hline Blood exchange in severe cases & 87 & 32.8 & 68 & 25.7 & 110 & 41.5 & 69 \\
\hline
\end{tabular}

*Overall percent score is $71 \%$

The mean overall percent score for all three domains was $71 \%$.

\section{Discussion}

Neonatal jaundice is one of the most common disorders world-wide. In time and proper management to reduce serious neurological complications depends on mother's knowledge and beliefs about neonatal jaundice. The highest percentage $43,8 \%$ of mothers were in the age group 20 - lowest percentage of correct responses was $14 \%$ with percent score $61 \%$ regarding frequent wash of the baby . Overall percent score for this domain was $71 \%$ as shown in the Table (5). 
Regarding educational level , $34.7 \%$ of mothers were with secondary level of education compared to $12 \%$ of secondary education by [13] in Nigeria, while $48 \%$ of respondents of (10) educated up to primary level , and $13.5 \%$ of [9] in Iran had high school education $[9,10,13]$.

The proportion of mothers with positive previous history of neonatal jaundice $38.8 \%$, while the findings of $[9,12]$ were $23 \%$, $72.88 \%$ in Iran and $55.7 \%$ in Nigeria[13][9,12,13] The site of jaundice detection as stated by the included mothers were $36.2 \%$ for skin , $32.1 \%$ in eyes , $29.5 \%$ in face , $23.8 \%$ in palms and feet while the results of(14) in Malaysia skin $95.4 \%$, eye $90.9 \%$, palms and feet $56.2 \%$ [14]. The main source of information regarding neonatal jaundice was family /relatives $39.7 \%$, followed by health workers $30.6 \%$, while the results of [13] mothers in Gwaza local government area of Borno state,Nigeria was family $33.0 \%$, friends $59.4 \%$ and medical personnel $5.7 \%$,while the findings of [9] revealed that two thirds of participants indicated antenatal clinic as a main source of information[9,13]. The knowledge responses of the included samples regarding the correct definition of jaundice which is the yellowish coloration of face and eyes of the newborn $57.7 \%$ which is lower than $90 \%$ by a previous study in Iraq [9] also $66.7 \%$ of the mothers stated that appearance of jaundice in the first day needs immediate medical consultation, this is because hyperbilirubinemia in the first 24 hours often result due to hemolytic disorder of the newborn $[15,16][9,15,16]$. In the current study, $20.3 \%$ of mothers had misconception that is normal to continue jaundice for 8 weeks, while more than $60 \%$ of mothers of [9] affirmed jaundice lasting more than 2 weeks is not abnormal and $75 \%$ were not aware that neonatal jaundice of early onset was abnormal and needed urgent treatment [9]. The health implications of neonatal jaundice related to neurological effects of unconjugated hyperbilirubinemia as severely affected babies develop brain damage with attendant morbidity and or even mortality [4] and in this study $46.4 \%, 42.2 \%, 29.4 \%$ and $27.2 \%$ answered correctly regarding death, brain damage, mental retardation and deafness respectively.

The findings of a study[14] in Malaysia $66.2 \%$ of mothers stated death ,42.9\% deafness , $51.3 \%$ mental retardation while the findings of another Malaysian study [17]) $71.7 \%$ and $69.7 \%$ of mothers answered that severe jaundice could result in death and brain damage [14,17]. A large population of [11] in Provincial general hospital, Badulla had stated5.4\% for mental handicap $.6 .5 \%$ for neonatal death [11].

Treatment options as claimed by the mothers in the current study was highly correct $63.4 \%, 37 \%$ and $46 \%$ for phototherapy ,exchange blood transfusion and exposure of the newborn to sun which are lower than the findings of in selected village of Puducherry $93.9 \%, 45.5 \%$ for phototherapy, exchange blood transfusion[10] ,while Harrison et al [18] revealed that $36 \%$ of postpartum mothers 
were in favor of using sun light to treat neonatal jaundice $[10,18]$. In Badulla[11] , $44 \%$ of mothers were aware of phototherapy as a standard treatment of neonatal jaundice , $14.1 \%$ were aware for exchange transfusion as a treatment for jaundice. A study conducted by [3] in Nigeria had also justified phototherapy and exchange transfusion remain the standard treatment of neonatal jaundice $[11,3]$.

\section{Conclusions}

The overall mean percent score of knowledge of the mothers regarding neonatal jaundice was good. It was good for definition and treatment, fair for complications of neonatal jaundice.

\section{Recommendations}

1-The study could serve as a stimulant for further researches with larger sample size.

2-There is continuous need for a targeted education and awareness program for mothers belonging to different health centers.

\section{References}

[1] Andreoli T, Carfenter C. Cecil. Essentials of Medicine. (2001) 5th ed. Philadelphia:W.B. Saunders: 371-2.

[2]Omar C., Hamza S., Bassem AM., Mariam R., Urinary tract infection and indirect hyperbilirubinemia, North American Journal of Medical Sciences, 2011, 3, 12: 544-547.

[3]Rodrigo B. K. N. R., Cooray G., Neonatal jaundice and its management .KAP of Community Health Workers in Nigeria.Sri Lanka Journal of Child Health, 2011, 40, 4: 164-168.
[4]Behrman R, Kliegman R, Jenson H, editors.Nelson Text book of Paediatrics. 17th ed.Philadelphia: W.B. Saunders; 2004: 52399.

[5]Daniel OJ. An old traditional herbal remedy for neonatal jaundice with a newly identified risk, Journal of Pediatric Child Health, 2011, vol.29:292.

[6]Chai, H. knowledge, attitudes and practices of Community Health Workers in Nigeria. BMC Public Health, 2006, 6: 19-25. [7]Khalesi N., Rakhshani F. Knowledge, attitude and behaviour of mothers on neonatal jaundis,Journal of Pakistan Medical Association, 2008, 58, 12: 671-674.

[8]Harry N. Boone JR, Deborah A. Boone . Analyzing Likert data, Journal of Extension , 2012,vol.50,No.2,Toos of the Trade,20T2. [9]Rabiyee Poor S, Gheibi S, Jafari S . knowledge and attitudes of postnatal mothers on neonatal jaundice in Motahar hospital ,Iran. Journal of Clinical Medicine Research, 2014: 3(1): 1-5.

[10]Dash M, A descriptive study to assess the knowledge and attitudes on neonatal jaundice among the mothers in a selected village of Puducherry . Journal of Medical and Health Sciences, 2013, 2, 3:41-46.

[11]Rodrigo Bk NR, Cooray G. The knowledge, attitudes and behaviors on neonatal jaundice of postnatal mothers :Provincial general hospital, Badulla, Srilanka Journal of Child Health , 2011,40(4):164 -168.

[12] Vaez A. knowledge and attitudes of mothers on neonatal jaundice in Saravan 
,Iran ,Easteren Kentucky University.Honors

Thesis : 337 .

[13]Bello , M , Yahaya ,SJ ,Mary A et al . Neonatal Jaundice: KAP of mothers in Gwaza local government area of Borno state . North Eastern Nigeria, International $\mathbf{J}$ of Health Care Sciences, 2014, Vol:1 ,Issue 1:7-12.

[14]Ng Sy , Chang Sy. What do mothers know about neonatal jaundice? Knowledge, attitudes and practices of mothers in Malaysia, Original article . Med Journal of Malaysia 2014 ,vol:69 ,No. 6 :252-256.

[15] Jacob A. A comprehensive text book of Mid wiferry ,2nd edition :588-90.

[16] Ghani O , Paul UK: Essential Pediatrics .CBS publication 6th edition RE, Khiegman RM , Jenson ,H B Editors . Nelson Text book of Pediatric ,16th ed. Philadelphia ,Sounders ,2005:169-176.

[17]Boo -NY, GanCY, GianYw et al : Malaysia mothers knowledge and practices on care of neonatal jaundice .Med Journal of Malaysia ,2011, 66 ( 3 ) :239-43.

[18]Harrison SL, Buettner PG, Macheanau. Why Do Mothers still sun their infants. Journal ofPediatric Child Health 1999, 35(3) : 296-9. 